Conclusions Results of our study suggest that combined general anaesthesia with truncal blocks such as TAP or QL for appendectomy in children may lengthen operative time, reduce the needs in analgesics, but do not effect on general outcomes.

\section{THE IMPACT OF INTRAVENOUS LIDOCAINE IN CHILDREN AND YOUNG PEOPLE UNDERGOING SPINAL FUSION SURGERY: THE EXPERIENCE IN A UK SPECIALIST CHILDREN'S HOSPITAL}

JE Bordoni*, S Siew, J Keough, M McMonagle, R Ravi, R Diwan, I Okonkwo. Alder Hey Children's Hospital NHS Foundation Trust, Liverpool, UK

\subsection{6/rapm-2021-ESRA.134}

Background and Aims The use of intravenous lidocaine therapy (IVLT) improves pain outcomes in certain adult populations, however, little evidence exists in paediatric populations. We aim to evaluate its impact in patients with adolescents idiopathic scoliosis(AIS) undergoing primary posterior spinal instrumentation and fusion (PSIF).

Methods ASA1 and ASA2 patients over 12-years-old undergoing PSIF surgery for AIS between January 2017 and December 2020 were reviewed retrospectively. Demographic data, anaesthetic and pain management were evaluated alongside postoperative outcome measures.

This service evaluation was deemed no to require ethical approval (http://www.hra-decisiontools.org.uk/research/docs/DefiningResearchTable_Oct2017-1.pdf) by our local clinical governance committee (Audit No. 6351)

Abstract 134 Table 1 Outcomes and characteristics of 45 patients undergoing PSIF

\begin{tabular}{|c|c|c|c|c|}
\hline & & 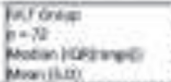 & 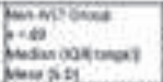 & Focka \\
\hline \multirow{9}{*}{ g } & havid & gaxessmen & monisestrit & 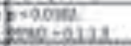 \\
\hline & 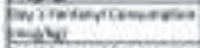 & 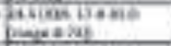 & 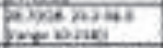 & $\sin =12$ \\
\hline & 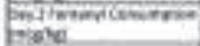 & 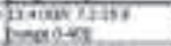 & 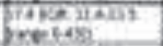 & fowow \\
\hline & Holathesy & 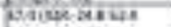 & 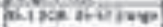 & Habes \\
\hline & 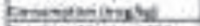 & Deasitul & brome & 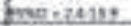 \\
\hline & 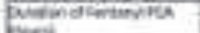 & 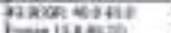 & 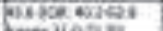 & Foces \\
\hline & Yers: & Es:14:52 & 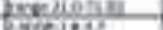 & 280.1111 \\
\hline & 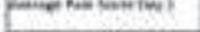 & monstionos & fancies. & 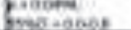 \\
\hline & penevialinewtans & 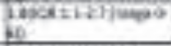 & 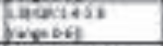 & Guation \\
\hline \multirow{4}{*}{$\frac{5}{5} \frac{2}{2}$} & Foiven & 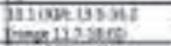 & 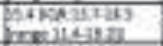 & Folist \\
\hline & Fis & swonis & pionis in & $\begin{array}{l}\text { grave } \\
\text { posis. }\end{array}$ \\
\hline & $\lim _{i \rightarrow 2}$ & $\begin{array}{l}\text { whinen } \\
\text { gonirs }\end{array}$ & Eviviow & benting \\
\hline & Boneriverviant & 13ak & tion 10 & Konghe \\
\hline \multirow{4}{*}{$\frac{3}{5}$} & 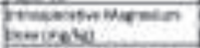 & papor wos & 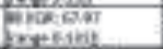 & 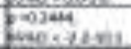 \\
\hline & 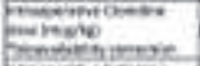 & Howerids & 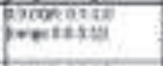 & 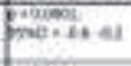 \\
\hline & 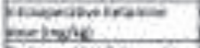 & Wocerast & 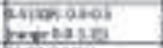 & Fonsed \\
\hline & 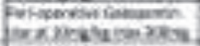 & monowe & Binentione & Foosen \\
\hline \multirow{3}{*}{$\frac{71}{31}$} & rownesty & कmprov & mave & granowist \\
\hline & winhe & Pantaning & 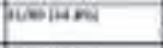 & 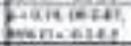 \\
\hline & GWINON & Drsthe & 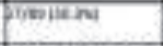 & 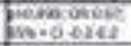 \\
\hline \multirow{3}{*}{$\frac{5}{2}$} & 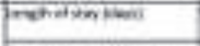 & 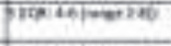 & कan & Faned \\
\hline & fasor Woustians & mocinivento & 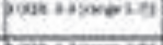 & Eacha \\
\hline & 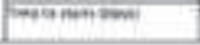 & 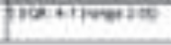 & 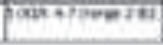 & Gration \\
\hline
\end{tabular}

Results 162 patients with a median age of 15.2(IQR:13.6-16.5 [range 11.4-19.2])years underwent PSIF for AIS. 33/162 $(20.4 \%)$ were male and $129 / 162(79.6 \%)$ female. $73 / 162$ (45.1\%) received IVLT at a median infusion-rate of $1.8(\mathrm{IQR}$ : 1.5-1.9 [range 1.1-2.0]) $\mathrm{mg} / \mathrm{kg} / \mathrm{hr}$. These patients required significantly less fentanyl: intraoperatively $(p=0.0182,95 \%$ $\mathrm{CI}=0.1-1.3)$, on day-1 $(\mathrm{p}=0.0032 ; 95 \% \mathrm{CI}=1.6-7.6)$ and day-2 $(\mathrm{p}=0.0104 ; 95 \% \mathrm{CI}=0.8-6.5 \quad$ (see table 1$)$; reported similar/ lower pain scores (day 1: $\mathrm{p}=0.0494 ; 95 \%$ CI $0.0-0.8$ ) and attained rehabilitation goals in similar timeframes.

Conclusions We observed the use of intraoperative IVLT to be associated with a significant reduction in early opiate requirements in paediatric PSIF, suggesting patients may benefit from earlier conversion from intravenous to oral opiates. This change has been implemented within our local Enhanced Recovery After Surgery Programme to facilitate earlier mobilization and discharge. Our patients reported similar levels of comfort and attained their rehabilitation goals in a similar timeframe. Further review and study is required to determine the optimal components and dosing within paediatric PSF ERAS programmes.

\section{Peripheral nerve blocks}

\section{IPACK AND ADDUCTOR CANAL BLOCK VS PERIARTICULAR INJECTION; ENHANCES POSTOPERATIVE PAIN CONTROL IN ANTERIOR CRUCIATE LIGAMENT (ACL) REPAIR: A RANDOMIZED CONTROLLED TRIAL}

A AlJa'bari*. DMF Hospital, Riyadh, Saudi Arabia

\subsection{6/rapm-2021-ESRA. 135}

Background and Aims Motor-sparing peripheral nerve blocks, such as the infiltration between the popliteal artery and capsule of the knee (IPACK) and the adductor canal block (ACB), may augment PAI in multimodal analgesic pathways for knee surgery, but supporting literature remains rare. We hypothesized that ACB and IPACK would lower pain on ambulation on postoperative day (POD) 1 compared to PAI alone.

Methods This triple-blinded randomized controlled trial included 50 patients undergoing ACL repair. Patients either received (1) a PAI (control group, $\mathrm{n}=26$ ) or (2) an iPACK with an ACB (intervention group, $\mathrm{n}=24$ ). The primary outcome was pain on ambulation on POD 1. Secondary outcomes included numeric rating scale (NRS) pain scores, patient satisfaction, and opioid consumption.

Results The intervention group reported significantly lower NRS pain scores on ambulation than the control group on POD 1( 3.3 [2.7 to 4.0]; P <0.001). In addition, NRS pain scores on ambulation on POD 0 (3.5 [2.7 to 4.3]; $\mathrm{P}$ $<0.001)$ and POD 2 (1.0 [1.0 to 1.9 ]; $\mathrm{P}=0.033)$ were significantly lower. Patients in the intervention group were more satisfied, had less opioid consumption $(\mathrm{P}=0.005$, PACU, $\mathrm{P}=0.028$, POD 0$)$, less intravenous opioids $(\mathrm{P}$ $<0.001)$, and reduced need for intravenous patient-controlled analgesia $(\mathrm{P}=0.037)$.

Conclusions The combination of iPACK to ACB significantly improves analgesia and reduces opioid consumption after ACL repair compared to PAI alone. This study strongly supports iPACK and ACB use within a multimodal analgesic pathway. 